\title{
Rural Healthcare Infrastructural Disparities in India: a Critical Analysis of Availability and Accessibility
}

\section{MOHD TAQI ${ }^{1 *}$, SWATI BIDHURI ${ }^{2}$, SUSMITA SARKAR ${ }^{3}$, WANI SUHAIL AHMAD ${ }^{4}$, PADMA WANGCHOK ${ }^{5}$}

\author{
${ }^{1}$ Assistant Professor, Department of Geography, Govt. PG College Bhadarwah, Jammu \\ $-182222$ \\ 2,3,4 Research Scholar, Department of Geography, Jamia Millia Islamia - 110025 \\ ${ }^{5}$ Assistant Professor, Department of Geography, Govt. Degree College Leh, Ladakh - \\ 194101
}

\section{Email: taqizaik@gmail.com}

Received: December 28, 2016 l Revised: March 16, 2017| Accepted: March 23, 2017

Published online: April 10, 2017

The Author(s) 2017. This article is published with open access at www .chitkara.edu. in/Publications

\begin{abstract}
Health and well being of human resource plays an important role in the economic as well as social development of the country. To ensure better health of the people an adequate healthcare infrastructure is of primary importance. Inadequate infrastructure generally leads to poor quality of health services which is positively dangerous to health and welfare of the community at large. About $68 \%$ of India's population still lives in rural areas, yet healthcare infrastructures in these areas are in pathetic condition. There are very few government health centers and even those are devoid of most of the medical facilities and personnel's. Although the National Rural Health Mission (NRHM), launched in 2005 has made significant progress in the healthcare infrastructure (mainly in physical infrastructure) in rural areas and has impacted the lives of rural masses to some extent but it has simultaneously failed to bring desired results because of lack of implementation. So the accessibility and availability of health facilities as well as delivery of quality services in the rural areas deserve considerable attention from planners, researchers and healthcare workers. In this context, the present paper critically examines and evaluates the disparities in availability as well as accessibility of health infrastructure in rural areas of India.
\end{abstract}

Keywords: Rural, Healthcare, Disparity, Availability, Accessibility.
Journal of Multidisciplinary Research in Healthcare Vol-3, No-2, April 2017 pp. 125-149 
Taqi, $M$

Bidhuri, $\mathrm{S}$

Sarkar, $S$ Ahmad, WS Wangchok, P

\section{INTRODUCTION}

The health and well being of the people of a country largely depends on well developed, accessible and effective healthcare infrastructure. Also healthcare infrastructure is an important indicator for analyzing the healthcare policy and welfare mechanism in the country. India is $2^{\text {nd }}$ most populous country in the world, and it also has largest rural population in the world. Although India has achieved robust economic growth in the last few decades and has become one of the world's fastest and most dynamic big economies, it has performed poorly in terms of health sector development. Today health sector in India particularly in rural areas is in a debilitating condition with lack of proper physical infrastructure, manpower and necessary drugs.

Recognizing the importance of health and well being of the people in development and also the importance of healthcare infrastructure in improving health, the Government of India launched the National Rural Health Mission (NRHM) in 2005 to strengthen the rural healthcare infrastructure in the country. The NRHM aims to provide an efficient and effective healthcare to the underserved rural areas in the country with special focus on the availability, accessibility, equitable and affordable health care services.

Although India has achieved considerable progress in health infrastructure under NRHM launched in 2005, the progress has been quite uneven across regions with large-scale interstate disparities in terms of availability and accessibility of healthcare services. The major issues in the rural healthcare are

i. Inadequate health infrastructure.

ii. Lack of proper healthcare facilities and skilled human resource in the existing health centres.

iii. Inefficiency and in accessibility of healthcare infrastructure in terms of population coverage.

iv. Lack of connectivity in the healthcare centres at different levels.

Thus in context of the issues given above, the paper seeks to analyze the present scenario of disparities in the availability and accessibility of healthcare infrastructure in rural areas.

\section{OBJECTIVES OF THE STUDY}

The main objectives of the present study are as follows

1. To analyze the spatial disparities in the availability of physical infrastructure as well as human resources.

2. To asses and compare the overall facilities available at each levels of health center. 
3. To analyze the spatial disparities in peoples accessibility to physical infrastructure and human resources.

\section{DATABASE AND METHODOLOGY}

The present paper is solely based on secondary data. Data pertaining to the rural population, rural healthcare infrastructure, maps of the study were collected from

i. Census of India (2001, and 2011). Published by Registrar General, Government of India.

ii. Bulletin on Rural Health Statistics (2006, 2011, and 2015). Published by Ministry Of Health and Family Welfare, Government of India

iii. Maps of India

The analysis carried out in the present paper is quantitative and descriptive. Two most important components of health care infrastructure that is Availability and Accessibility have been taken to analyze the spatial disparities across various states of India in terms of rural healthcare infrastructure. In order to analyze Availability and Accessibility following parameters have been selected,

\subsection{Availability}

Includes, shortfall in physical infrastructure (gap between the required and available infrastructure) and overall Facilities available at health centres which includes various parameters as given below,

SCs with regular water and electric supply, PHCs with labour room, operation theatre, at least 4 beds, proper electric and water supply, and referral transport, $\mathrm{CHCs}$ with functioning laboratory, operation theatre, labour room, and stabilization units for new born, with at least 30 beds, referral transport.

Various parameters for availability in terms of human resource includes: shortfall in the Health worker (male and female) at sub centres, shortfall of doctors at PHCs and no. of PHCs without doctors, shortfall of total specialists and paramedical staff (includes Laboratory technicians, Pharmacists, and Radiographers) on CHCs

\subsection{Accessibility}

It has been analyzed in terms of;

- Average rural population coverage by SCs, PHCs, and CHCs as against standard population norms
Rural Healthcare Infrastructural Disparities in India: a Critical Analysis of Availability and Accessibility 
Taqi, $\mathrm{M}$

Bidhuri, S

Sarkar, $\mathrm{S}$

Ahmad, WS

Wangchok, $\mathrm{P}$

Table1: Population Norms.

\begin{tabular}{ccc}
\hline Health care Centre & Area \\
& Plain & Hilly/Tribal \\
\hline Sub Centre (SC) & 5000 & 3000 \\
Primary Health Centre (PHC) & 30,000 & 20,000 \\
Community Health Centre & $1,20,000$ & 80,000 \\
\hline
\end{tabular}

Source: Rural Health Statistics - 2015

- Ratio of doctors and specialists to the rural population as against standard population norms

- SCs and PHCs with all weather Motorable approach road.

Simple percentages of each parameters and composite percentage of all parameters (in terms of parameters in the available facilities) have been taken to measure disparity in availability and accessibility.

ArcGIS software has been used to combine spatial with non-spatial data in order to get better picture of the situation which includes mapping.

The present study is confined to Indian states only, and analysis for Andhra Pradesh and Telangana have been shown collectively due to non-availability of separate data.

\section{HEALTHCARE INFRASTRUCTURAL SYSTEM IN RURAL INDIA}

In rural India heath care infrastructure has been developed as a three tier system in a hierarchy based primarily on the population norms as follows:

\subsection{Sub Centre (SC)}

The Sub Centre is the most peripheral and is point of first contact between the primary healthcare system and the rural community. Sub centres cover a population of 3000 in the hilly/tribal areas and 5000 in the plain areas. The Sub Centres are assigned the task relating to Interpersonal communication in order to bring about behavioral change, Provide services in relation to maternal and child health, Family welfare, Nutrition, Immunization and Control of communicable diseases.

\subsection{Primary Health Care (PHC)}

Primary health care is the first contact point between rural community and the medical officer. It acts as a referral unit for sub centre. PHCs are the 
cornerstone of the rural healthcare services. These are the first point where the rural people can directly report or can be referred from Sub Centres to qualified doctors for curative, preventive and promotive healthcare. A typical PHC covers a total population of 20,000 in the tribal/hilly areas and 30,000 in the plain areas. The PHC's are assigned with the task to provide an integrated curative, preventive, and rehabilitative healthcare services, Medical care for Patients, Maternal and child health care including family planning, nutrition and immunization services, and control of communicable diseases.

\subsection{Community Health Centre (CHC)}

$\mathrm{CHCs}$ serves as a referral centre for PHC and also provides facilities for obstetric and specialist consultation. As according to the population norms, a typical CHC have to serve a population of 80,000 and 1, 20,000 in hilly/tribal and plain areas respectively.

The pattern of human resource or manpower at all three levels of health care that is SC, PHC, and CHC are set according to Indian Public Health Standards (IPHS) which is in turn dictated by the Ministry of Health and Family Welfare Government of India. IPHS are set of uniform standards aimed at improving the quality of healthcare delivery in the country. The minimum required IPHS for human resources at SCs, PHCs and CHCs are given in the table -2 below:

Table 2: Human Resource Pattern.

\begin{tabular}{ll}
\hline A) Human Resource for SCs & Number of posts \\
\hline 1. Health Worker (Female)/ANM & 1 \\
2. Health Worker (Male) & 1 \\
3. Voluntary Worker & 1 \\
Total & 3
\end{tabular}

\section{B) Human Resources for PHCs}

1. Medical Officer/Doctor 1

2.Pharmacist 1

3.Nurse Mid-wife 1

4.Health Worker (Female)/ANM 1

5.Health Educator 1

6.Health Assistant (Male) 1

7. Health Assistant (Female)/LHV 1 


\begin{tabular}{lll} 
Taqi, M & 8. Laboratory Technician & 1 \\
Bidhuri, S & 9. Other supporting staff & 7 \\
Sarkar, S & Total & 15 \\
Ahmad, WS & & \\
Wangchok, P & C) Human Resources for CHCs & \\
& 1.Medical Officer/Specialists & 4 \\
& 2. Nurse Mid-wife & 7 \\
& 3.Dresser & 1 \\
& 4.Pharmacist & 1 \\
5.Laboratory Technician & 1 \\
& 6.Radiographer & 1 \\
& 7.Other supporting staff & 10 \\
& Total & 25 \\
\cline { 2 - 2 } & & \\
& &
\end{tabular}

Source: Rural Health Statistics - 2015

\section{RESULT AND DISCUSSION}

\subsection{Disparities in the Availability: In terms of physical infrastructure and the facilities}

Availability of physical healthcare infrastructure is one of the most important pillars of health care systems at any area. Adequate infrastructure is fundamental to the provision and execution proper health services at all levels, and also determines the quality of services being provided. It is the foundation for delivering quality healthcare services. Unfortunately there is a widespread disparity in the availability of physical infrastructure in terms of SCs, PHCs, and CHCs in rural India. Some states have surplus infrastructure while others having shortfall of varying degrees.

\subsubsection{Sub Centres (SCs)}

Considering the availability of SCs Figure-1A reveals that most of the Indian sates in south, west, and north are surplus with respect to the required number as per the population norms. Whereas central, east and northeast states shows a shortfall of varying percentage ranging from 25 to 50 percent with Bihar and Meghalaya having highest shortfall, that is 48 and 44 percent (table - 3) respectively. In terms $f$ the whole country there is 20 percent shortfall in the $\mathrm{SCs}$ as per the population norm. 


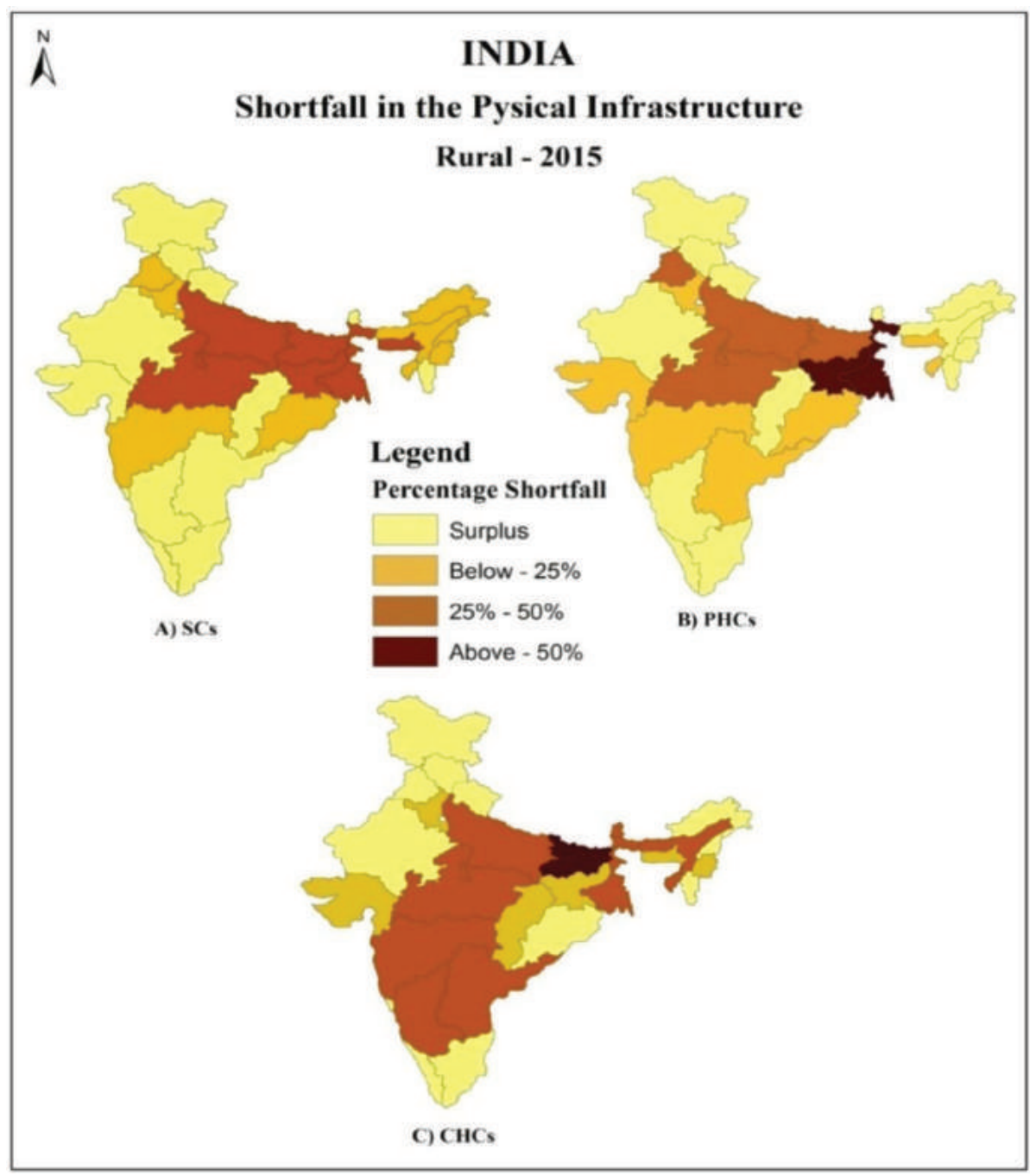

Rural Healthcare Infrastructural Disparities in India: a Critical Analysis of Availability and Accessibility

\section{Figure 1:}

Fig - 2 shows the cumulative percentage of SCs, PHCs and CHCs with over all facilities available. Considering the percentage of SCs with overall facilities available Fig $-2 \mathrm{~A}$ reveals that most of the states have above 50 percent SCs with overall facilities. However states like

Bihar, Jharkhand, Jammu \& Kashmir, and most of the states in the north east have less than 50 percent SCs with overall facilities Tripura being the lowest that is below $25 \%$. 
Taqi, $\mathrm{M}$

Bidhuri, S

Sarkar, S

Ahmad, WS

Wangchok, $\mathrm{P}$

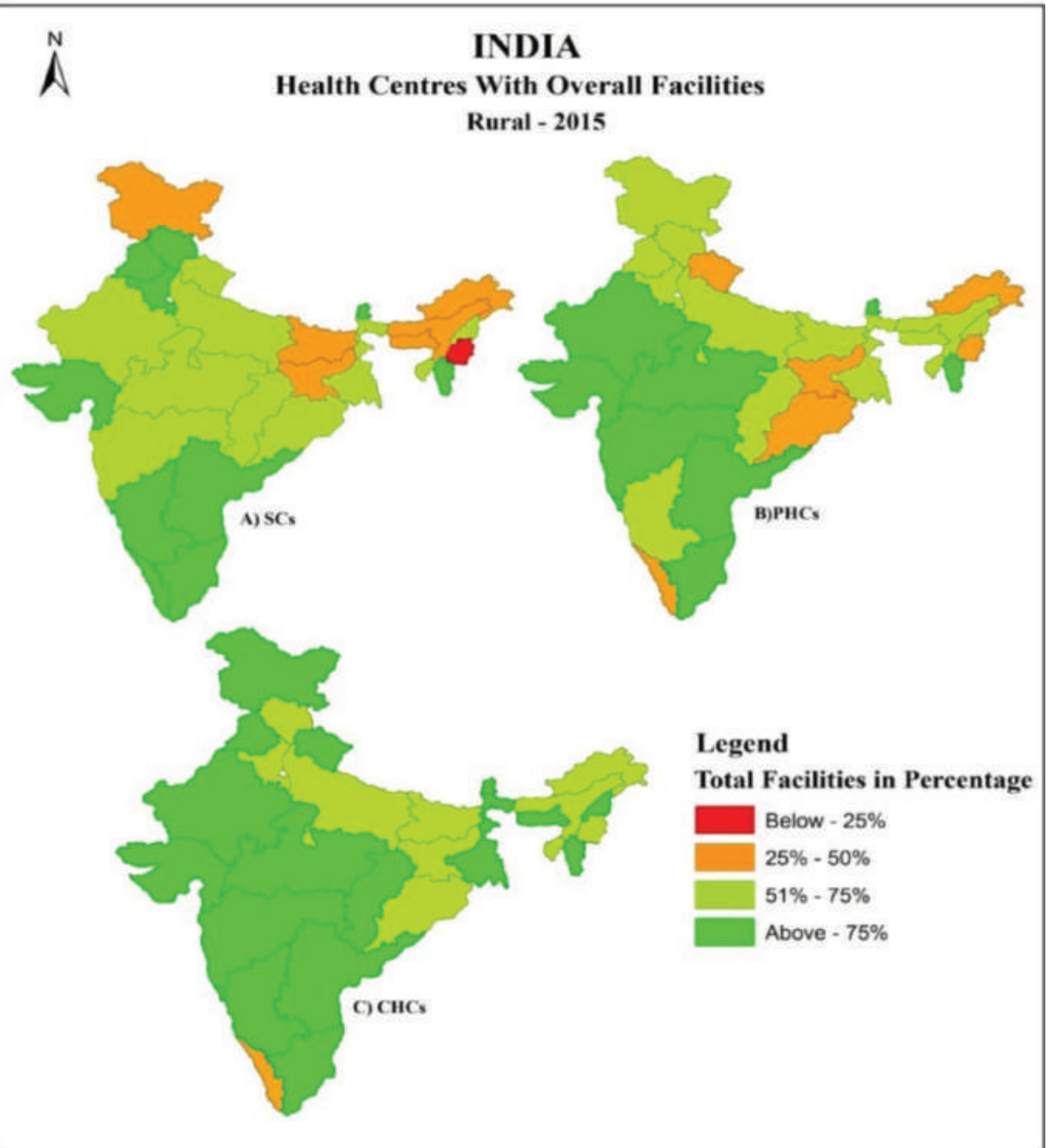

Figure 2:

\subsubsection{Primary Health Centres (PHCs)}

Table - 3 shows that on an average India has 22 percent shortfall in PHCs but in some states particularly West Bengal and Jharkhand shortfall is much higher than the national average that is 58 and 66 percent respectively. States like Uttar Pradesh, Bihar and Madhya Pradesh also had high degree of shortfall ranging from 25 to 50 percent (Fig - 1B). Compared to the national average, Haryana, Gujarat, Maharashtra, Odisha, Meghalaya, Tripura, Andhra Pradesh 
Table 3: Total Shortfalls in Health Centres - 2015.

\begin{tabular}{|c|c|c|c|c|}
\hline \multirow{2}{*}{$\begin{array}{l}\text { S. } \\
\text { No. }\end{array}$} & \multirow[t]{2}{*}{ State } & \multicolumn{3}{|c|}{ Shortfall in the Health Centres } \\
\hline & & Sub Centre (SC) & PHC & СHC \\
\hline 1 & Andhra Pradesh & $*$ & 11 & 40 \\
\hline 2 & Arunachal Pradesh & 10 & $*$ & $*$ \\
\hline 3 & Assam & 21 & $*$ & 37 \\
\hline 4 & Bihar & 48 & 39 & 91 \\
\hline 5 & Chhattisgarh & $*$ & $*$ & 20 \\
\hline 6 & Goa & $*$ & $*$ & $*$ \\
\hline 7 & Gujarat & $*$ & 3 & 1 \\
\hline 8 & Haryana & 22 & 16 & 20 \\
\hline 9 & Himachal Pradesh & $*$ & $*$ & $*$ \\
\hline 10 & Jammu \& Kashmir & $*$ & $*$ & $*$ \\
\hline 11 & Jharkhand & 35 & 66 & 22 \\
\hline 12 & Karnataka & $*$ & $*$ & 37 \\
\hline 13 & Kerala & $*$ & $*$ & $*$ \\
\hline 14 & Madhya Pradesh & 26 & 41 & 33 \\
\hline 15 & Maharashtra & 22 & 18 & 35 \\
\hline 16 & Manipur & 17 & $*$ & 15 \\
\hline 17 & Meghalaya & 44 & 4 & 4 \\
\hline 18 & Mizoram & $*$ & $*$ & $*$ \\
\hline 19 & Nagaland & 13 & $*$ & $*$ \\
\hline 20 & Odisha & 18 & 1 & $*$ \\
\hline 21 & Punjab & 15 & 26 & $*$ \\
\hline 22 & Rajasthan & $*$ & $*$ & $*$ \\
\hline 23 & Sikkim & $*$ & $*$ & 50 \\
\hline 24 & Tamil Nadu & $*$ & $*$ & $*$ \\
\hline 25 & Tripura & $*$ & 17 & 26 \\
\hline 26 & Uttarakhand & $*$ & $*$ & $*$ \\
\hline 27 & Uttar Pradesh & 34 & 33 & 40 \\
\hline 28 & West Bengal & 21 & 58 & 36 \\
\hline 29 & India & 20 & 22 & 32 \\
\hline
\end{tabular}

Rural Healthcare Infrastructural Disparities in India: a Critical Analysis of Availability and Accessibility

Source: Rural Health Statistics -2015 * Surplus 
Taqi, $M$

Bidhuri, $\mathrm{S}$

Sarkar, $S$ Ahmad, WS Wangchok, $\mathrm{P}$

and Telangana had low percentage shortfall. Rest all other states are surplus in terms of required PHCs.

As far as percentage of PHCs with overall facilities are concerned Fig - 2B shows that state Uttarakhand, Jharkhand, Odisha, Arunachal Pradesh, Tripura and Kerala had less than 50\% PHCs with overall Facilities available. Rest of all states has more than 50 percent and in some states even more than 75 percent $\mathrm{PHCs}$ with overall facilities available.

\subsubsection{Community Health Centres (CHCs)}

As far as availability of CHCs is concerned Table -3 shows only 12 states are in surplus and rest all states have shortfall of varying percentage. On an average India have 32 percent shortfall in CHCs with Bihar and Meghalaya being highest and Lowest that is 91 percent and 4 percent shortfall respectively. Uttar Pradesh, Madhya Pradesh, Maharashtra, Karnataka, West Bengal, Assam, Tripura, Andhra Pradesh and Telangana are among other states having shortfall ranging between 25 to 50 percent (Fig - 1C).

Fig $-2 \mathrm{C}$ reveals all Indian states except Kerala has more than 50 percent CHCs with overall facilities available, also most among them having above 75\% CHCs with overall facilities. Kerala was the only State which has less than 50 percent $\mathrm{CHCs}$ with overall facilities.

\subsection{Disparities in the Availability: In terms of Human Resource}

Human recourses or manpower is defined as "all people engaged in actions whose primary intend is to enhance health", Human resources for health are identified as one of the core building blocks of healthcare system (WHO's World Health Report 2006). Human resources include the whole range of specialists, doctors, paramedical staffs, health workers etc. at different levels of health centres. Proper availability of human resource is very critical in the whole system of healthcare service delivery to the people. The present disparities in the availability and shortfall of manpower at all levels of health centres are discussed below

\subsubsection{Shortfall at Sub Centres (SCs)}

As per the IPHS, typical SC must have two health worker that is male and a female each. But when analyzing the availability of health worker at SCs in rural India no state except Mizoram is in Surplus (Fig - 3). Most of the states had shortfall ranging between $25-50$ percent with Nagaland having highest and Manipur having lowest shortfall in terms of SC with health workers that is 50 and 5 percent respectively (table -4 ). On an average India have 32\% 


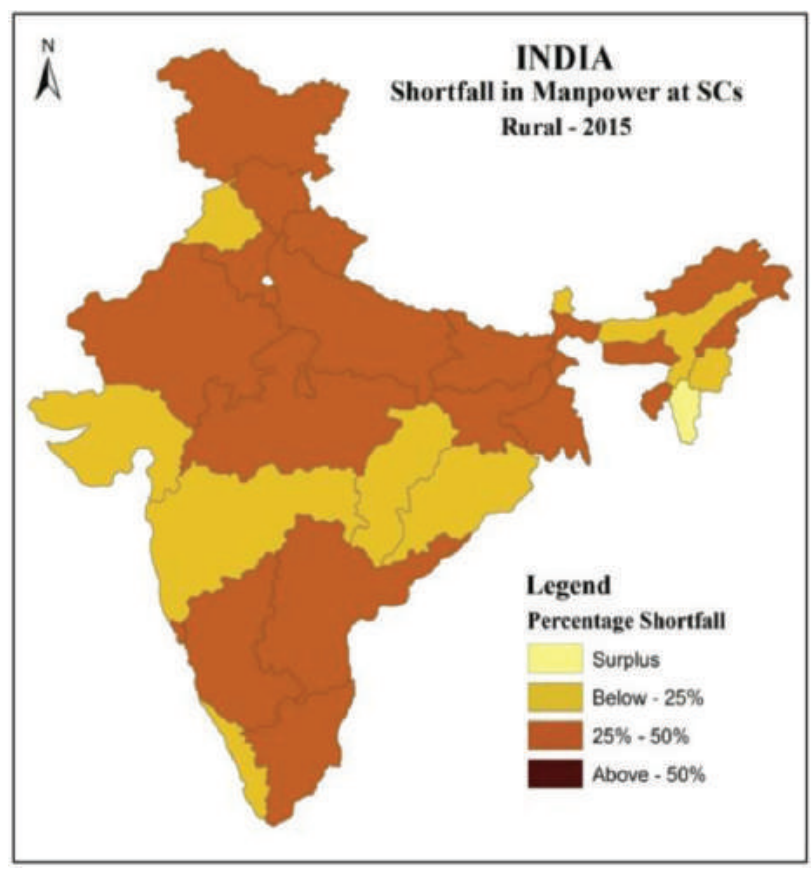

Rural Healthcare Infrastructural Disparities in India: a Critical Analysis of Availability and Accessibility

\section{Figure 3:}

shortfall of health workers in the available SCs with 15 states having shortfall above national average.

\subsubsection{Shortfall at Primary Health Centres (PHCs)}

Every PHC must be manned by one doctor/medical officer as per the IPHS. Considering the availability of doctors at PHC, fig $-4 \mathrm{~A}$ reveals that there is a wide disparity among various states. Though most of the states in the north, south and north eastern states had surplus doctors in PHCs but on the other hand there is a high degree of doctor's shortfall in the states like Chhattisgarh, Uttar Pradesh, and Gujarat with Chhattisgarh having the highest that is 54 percent (table -4$)$. Fig -5 shows the total percentage of PHCs functioning without doctor/medical officer. It is disturbing to note that some states like Chhattisgarh, Madhya Pradesh, Arunachal Pradesh, and Uttarakhand had almost half of the available PHCs without doctor, also out of 29 states 18 states had PHCs functioning without doctor. On an average about 10 percent of PHCs were functioning without doctor at national level, though when comparing the available doctors with required doctors at national level, India is in surplus in terms of availability. 
Taqi, M

Bidhuri, S

Sarkar, S

Ahmad, WS

Wangchok, P

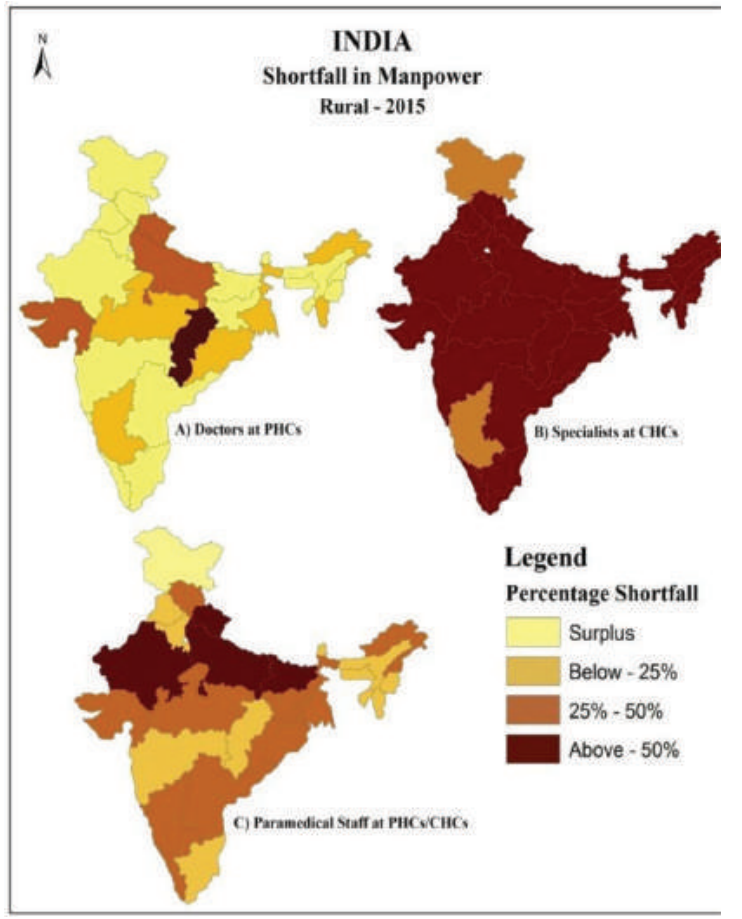

Figure 4:

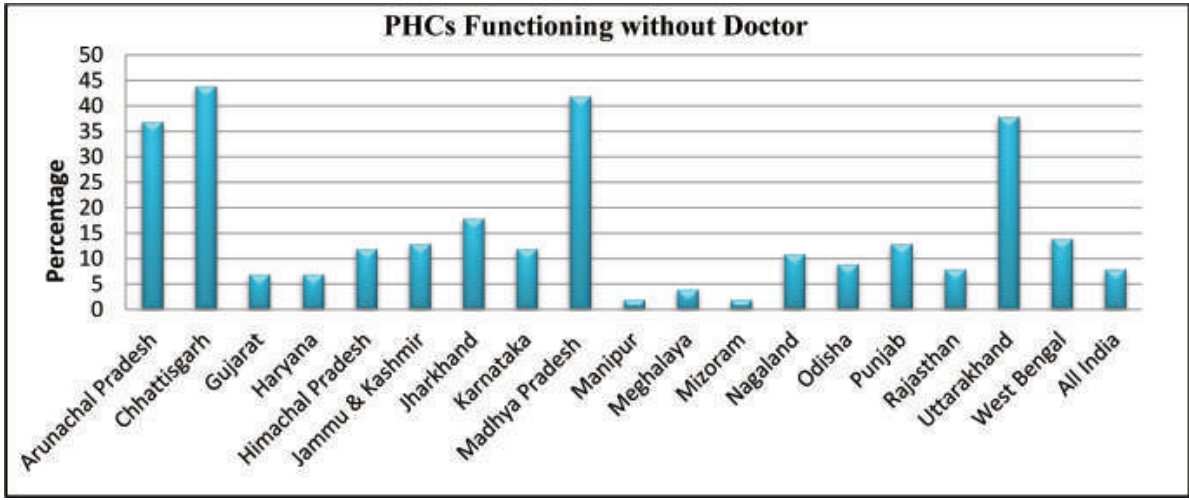

Figure 5:

\subsubsection{Shortfall at Community Health Centres (CHCs)}

According to the IPHS a typical CHC is supposed to have at least 4 specialists (that is Surgeon, Obstetrician, Physician and Pediatrician), but as fig - 4B 
Table 4: Total Shortfalls in Human Resources at Health Centres 2015.

\begin{tabular}{|c|c|c|c|c|c|}
\hline \multirow{2}{*}{$\begin{array}{l}\text { S. } \\
\text { No. }\end{array}$} & \multirow[t]{2}{*}{ State } & \multicolumn{4}{|c|}{ Health Centre wise Shortfall } \\
\hline & & $\begin{array}{c}\text { Health Worker } \\
\text { (Male/Female) } \\
\text { at SCs }\end{array}$ & $\begin{array}{l}\text { Doctors } \\
\text { at PHC }\end{array}$ & $\begin{array}{l}\text { Total Spe- } \\
\text { cialists@ } \\
\text { at CHC }\end{array}$ & $\begin{array}{c}\text { Total } \\
\text { Paramedi- } \\
\text { cal\# Staff at } \\
\text { PHC/CHC }\end{array}$ \\
\hline 1 & Andhra Pradesh & 34 & $*$ & 77 & 30 \\
\hline 2 & Arunachal Pradesh & 35 & 13 & 100 & 54 \\
\hline 3 & Assam & 13 & * & 80 & 3 \\
\hline 4 & Bihar & 44 & * & 78 & 78 \\
\hline 5 & Chhattisgarh & 16 & 54 & 87 & 20 \\
\hline 6 & Goa & 44 & $*$ & 75 & 37 \\
\hline 7 & Gujarat & 21 & 29 & 94 & 29 \\
\hline 8 & Haryana & 27 & * & 93 & 20 \\
\hline 9 & Himachal Pradesh & 28 & $*$ & 98 & 47 \\
\hline 10 & Jammu \& Kashmir & 38 & * & 50 & $*$ \\
\hline 11 & Jharkhand & 43 & $*$ & 83 & 45 \\
\hline 12 & Karnataka & 33 & 8 & 39 & 27 \\
\hline 13 & Kerala & 13 & $*$ & 96 & 38 \\
\hline 14 & Madhya Pradesh & 27 & 15 & 80 & 38 \\
\hline 15 & Maharashtra & 18 & $*$ & 60 & 24 \\
\hline 16 & Manipur & 5 & $*$ & 96 & 5 \\
\hline 17 & Meghalaya & 34 & * & 97 & 7 \\
\hline 18 & Mizoram & $*$ & 14 & 100 & 21 \\
\hline 19 & Nagaland & 50 & $*$ & 95 & 45 \\
\hline 20 & Odisha & 23 & 23 & 76 & 48 \\
\hline 21 & Punjab & 21 & * & 71 & 8 \\
\hline 22 & Rajasthan & 44 & $*$ & 77 & 52 \\
\hline 23 & Sikkim & 11 & $*$ & 100 & 26 \\
\hline 24 & Tamil Nadu & 38 & $*$ & 100 & 22 \\
\hline 25 & Tripura & 48 & $*$ & 96 & 25 \\
\hline
\end{tabular}

Rural Healthcare Infrastructural Disparities in India: a Critical Analysis of Availability and Accessibility 


$\begin{array}{lclcccc}\text { Taqi, M } & 26 & \text { Uttarakhand } & 48 & 38 & 79 & 60 \\ \text { Bidhuri, S } & 27 & \text { Uttar Pradesh } & 42 & 37 & 84 & 58 \\ \text { Sarkar, S } & 28 & \text { West Bengal } & 37 & 20 & 92 & 51 \\ \text { Ahmad, WS } & 29 & \text { India } & 32 & * & 81 & 36 \\ \text { Wangchok, P } & \text { S } & & \end{array}$

Source: Rural Health Statistics-2015, @ Specialists include: Surgeons, Obstetricians \& Gynecologist, and Physicians \& Pediatricians, \# Paramedical Staff Include:

Pharmacists, Laboratory technicians, and Radiographers, * Surplus.

reveals that no states in India fulfils the required number of specialists at CHCs. All Indian states except Jammu Kashmir and Karnataka had above 50 percent shortfall with Arunachal Pradesh, Mizoram, Sikkim and Tamil Nadu having 100 shortfall in specialists at CHCs. On an average India had 81 percent shortfall in specialists and added to this 17 states had shortfall above the national average.

\subsubsection{Shortfall of Paramedical Staff at PHC/CHC}

The paramedical staff is one of the most important parts of healthcare service delivery. Their proper availability is an important prerequisite for the efficient functioning of the healthcare system. Each PHC and CHC needs to be manned by one pharmacist and one laboratory technician respectively as per minimum requirement by IPHS. Fig - 4C reveals the total shortfall of paramedical staff (including pharmacists, laboratory technicians and radiographers) at PHCs and $\mathrm{CHCs}$ in rural India, which shows that all states in India have shortfall except in Jammu and Kashmir. Rajasthan, Uttar Pradesh, Bihar, West Bengal and Arunachal Pradesh have above 50 percent shortage of paramedical staff. India has on an average 36 percent shortfall in the paramedical staff at PHCs and $\mathrm{CHCs}$ with 13 states having shortfall above national average.

\subsection{Disparities in the Accessibility: In terms of Population Coverage by Health Centres}

Average population covered by a health centre is one of the most important parameters for analyzing the status of healthcare service delivery as well as accessibility of the people to a particular health centre. Its importance can be understood by the fact that the whole criteria of setting up a health centre are based on population norms. It can be also argued that there is a negative relationship between the population coverage by any health centre and accessibility of people to that centre that is more the population coverage less will be the accessibility. The present situation of health centre average population coverage in rural India is discussed below. 


\subsubsection{Average population covered by SCs}

In context of statement given above Fig -6 and 7 shows the average population covered by SCs in 2015 , which reveals that population coverage has not been same in different states. As per population norms when considering both hilly and plain areas, on an average SCs must serve a population of 4000 people. But looking at the figures below it can be noted that most of the states have SCs covering population above the required average.

On an average SCs had to serve above 5000 population at national level with Bihar and Uttar Pradesh among highest, that is above 70000 and 90000 respectively. States with SCs covering population below the required norm are mostly in north, northeast and south India. Other states with high population covered by SCs, that is above national average are Punjab, Haryana, Maharashtra, Madhya Pradesh, Jharkhand, Odisha, West Bengal, Assam and Meghalaya.

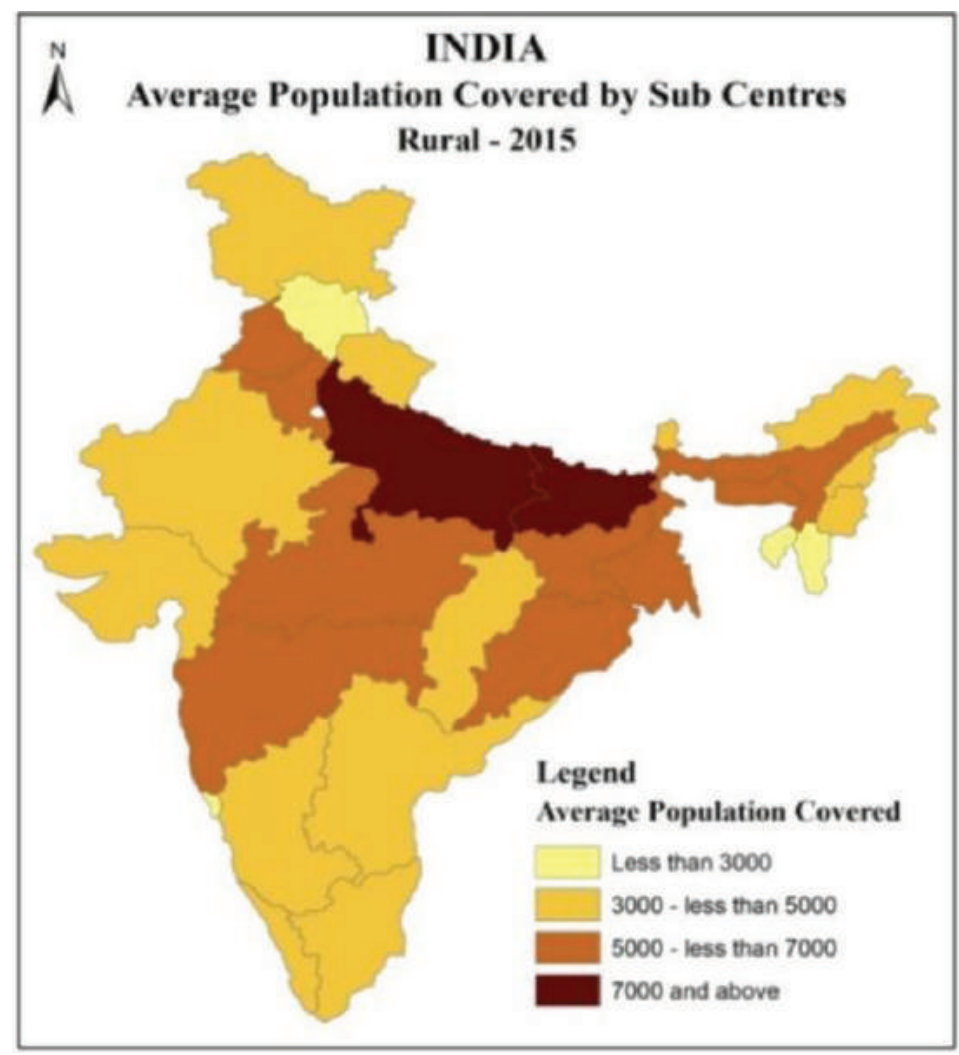

Rural Healthcare Infrastructural Disparities in India: a Critical Analysis of Availability and Accessibility 
Taqi, M

Bidhuri, S

Sarkar, S

Ahmad, WS

Wangchok, P

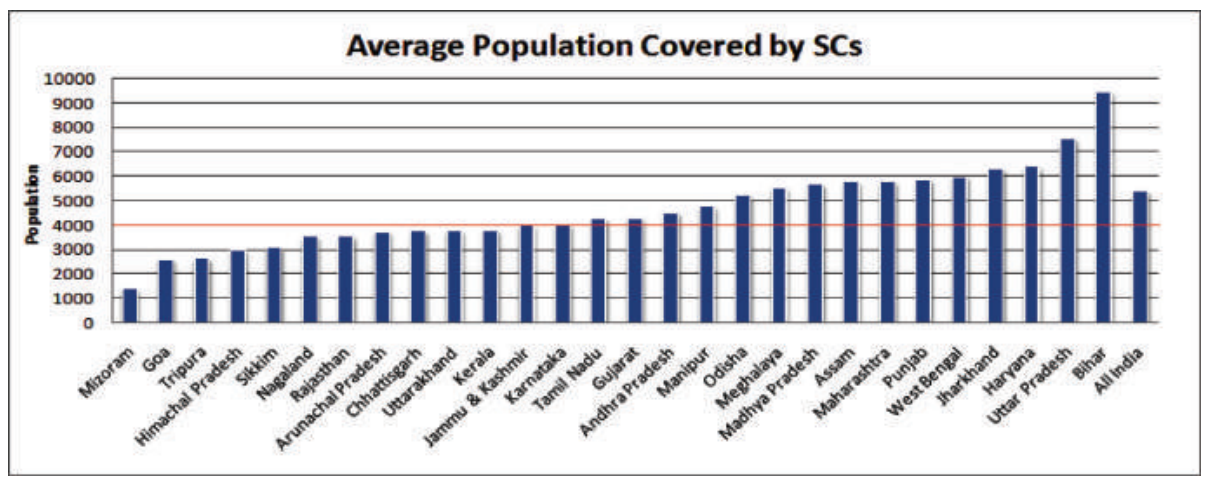

Figure 7:

\subsubsection{Average Population Covered by PHCs}

According to the population norms on an average a particular PHC need to serve 25000 people considering both hilly and plain areas. However looking at the fig -8 and 9, all the states except Andhra Pradesh, Mizoram, Nagaland, Himachal Pradesh, and Jammu and Kashmir had covered population above the required average. On an average PHC's had to serve population of above 30000 nationally with some states like Jharkhand, West Bengal, Bihar , Madhya Pradesh, Uttar Pradesh etc having population coverage by PHC's even beyond the national average.

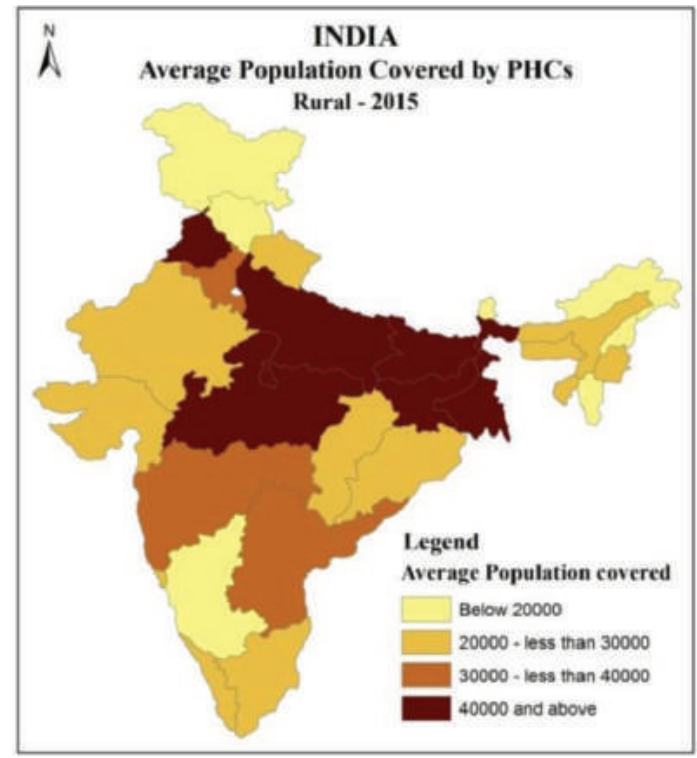

Figure 8: 


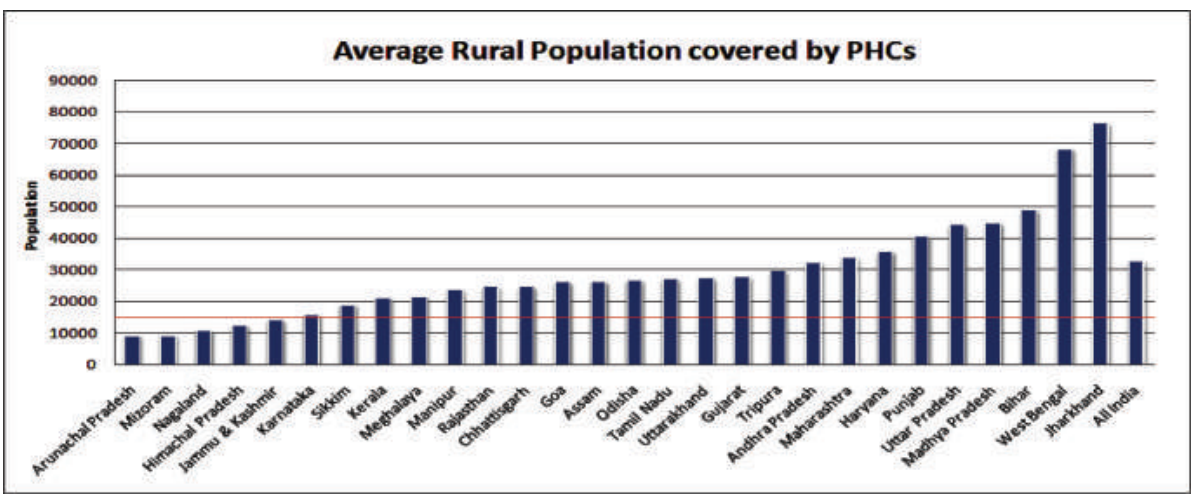

Rural Healthcare Infrastructural Disparities in India: a Critical Analysis of Availability and Accessibility

Figure 9:

25 out of 29 states all over the country having PHCs serving more than the average required norm explains the level of peoples accessibility to PHCs in the country.

\subsubsection{Average Population Covered By CHCs}

On an average a $\mathrm{CHCs}$ have to serve 100000 people as per the population norms. Considering this Fig - 10 and 11 reveals that most of the states in

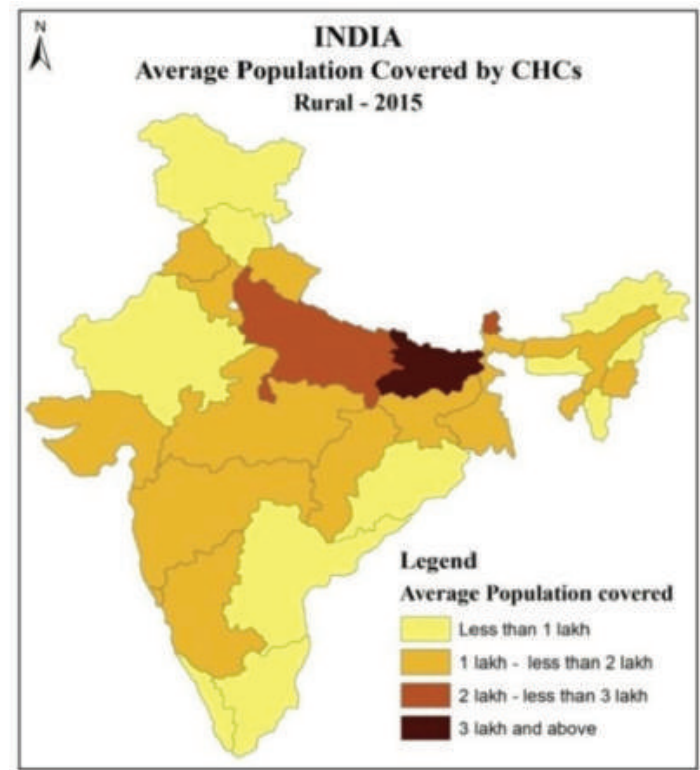

Figure 10: 
Taqi, $M$

Bidhuri, $\mathrm{S}$

Sarkar, $\mathrm{S}$

Ahmad, WS

Wangchok, P

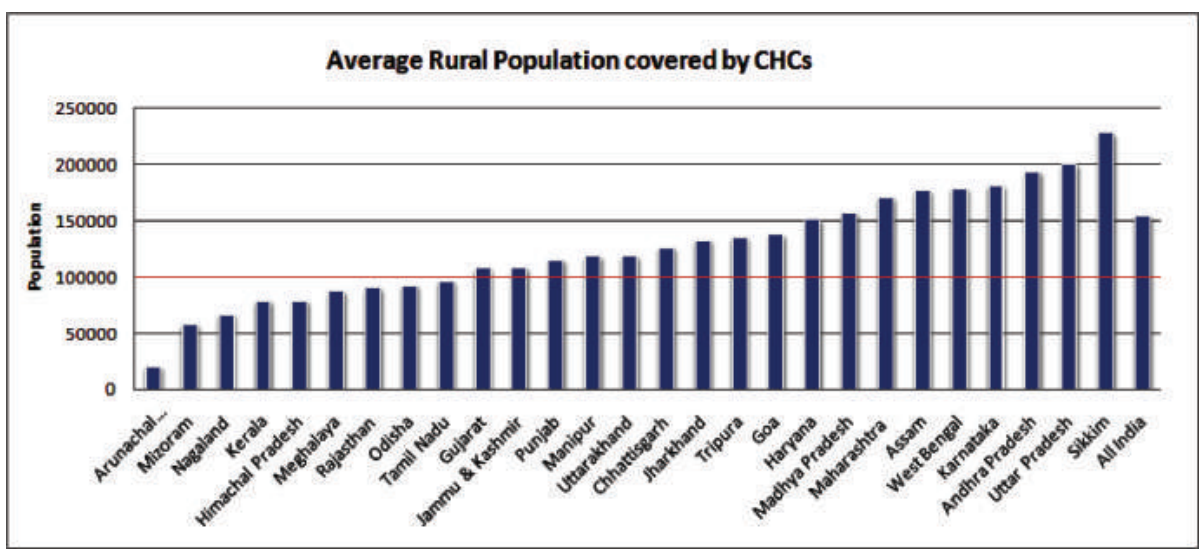

Figure 11:

central, north, east and western India are much above the average required population coverage. The all India population average coverage by a CHC is about 1.5lakh which also is above the population norm. Bihar has the highest population coverage by CHCs (that is above 13 lakh) followed by Sikkim, Uttar Pradesh, Andhra Pradesh and Telangana. Only 9 out of 20 states had coverage less than average population coverage.

\subsection{Disparities in the Accessibility: In terms of Doctor/Specialists Population Ratio}

Ratio of doctors at PHCs and Specialists at CHCs to the population is one of most sensitive indicator of healthcare service delivery mechanism. For a health system to function efficiently and deliver service effectively a healthy ratio of doctor to the population is a prerequisite. As per the population norms for PHC and CHC, every allopathic doctor/specialist on an average must serve 25000 and 1 lakh population respectively.

Considering the above norm, fig - 12 and 13 represents the present ratio of doctors to the population in rural India, in which most of the states have shown very poor ratio with West Bengal at the top that is 1 doctor per 85000 (which is 3 times higher than the required average), followed by Uttar Pradesh and Jharkhand (about 1: 70000), Chhattisgarh and Madhya Pradesh (above 1:50000), Bihar, Gujarat, Odisha, and Punjab having ratio above 1:35000.

States in the south, northeast, Jammu and Kashmir and Himachal in the north and Rajasthan in the west have much better doctor population ratio that is below the average ratio as per population norm. On an average India have a ratio of one doctor to about 30000 people. 


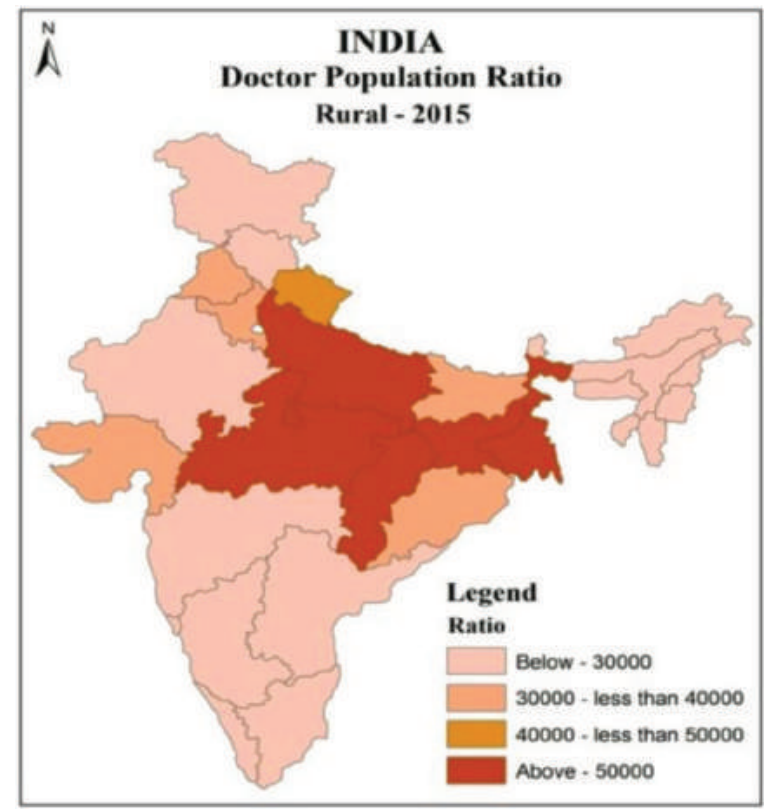

Rural Healthcare Infrastructural Disparities in India: a Critical Analysis of Availability and Accessibility

\section{Figure 12:}

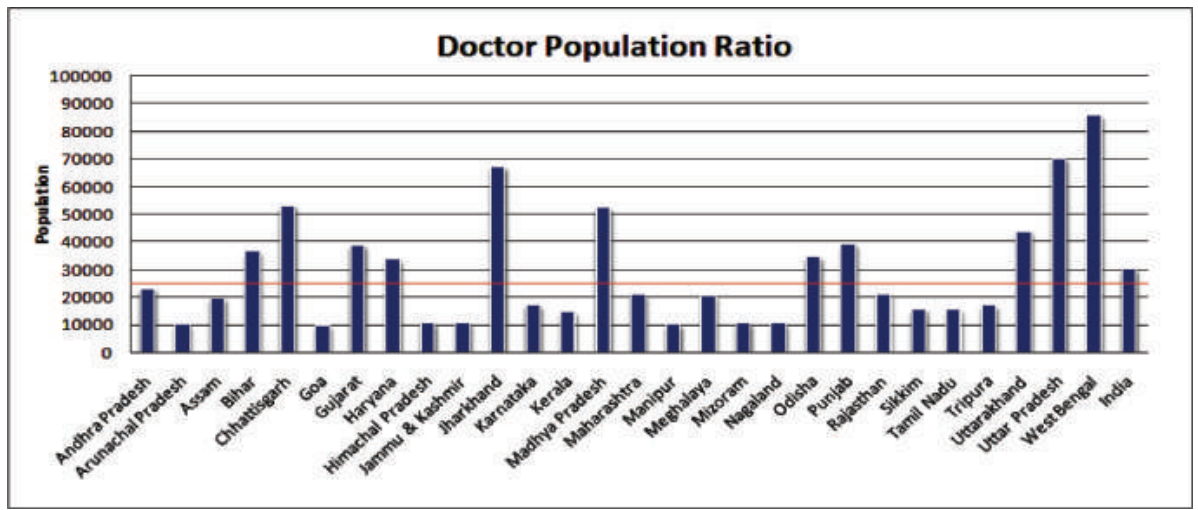

Figure 13:

On the other hand, looking at the specialist ratio to population, not a single state all over the country has an optimum ratio. It is quite very depressing to note that in some states like Bihar, Himachal Pradesh, Meghalaya, Arunachal Pradesh, Manipur and Tripura have ratio many times higher than the average ratio specified by Indian public health standards, also there is not a single specialist available at CHCs in Sikkim, Mizoram, and Tamil Nadu. 
Taqi, M

Bidhuri, S

Sarkar, S

Ahmad, WS

Wangchok, P

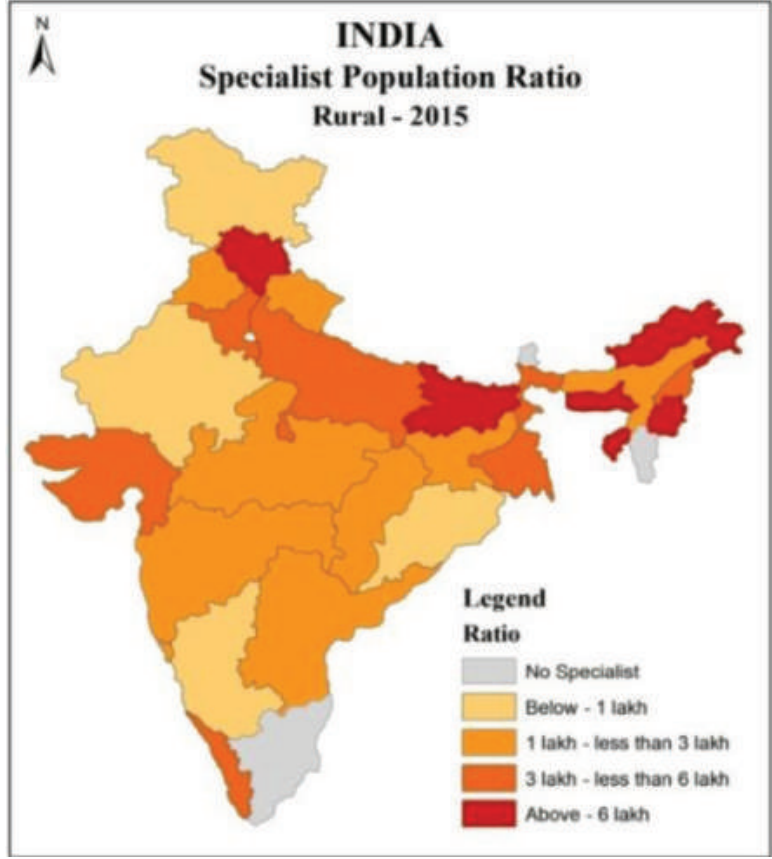

Figure 14:

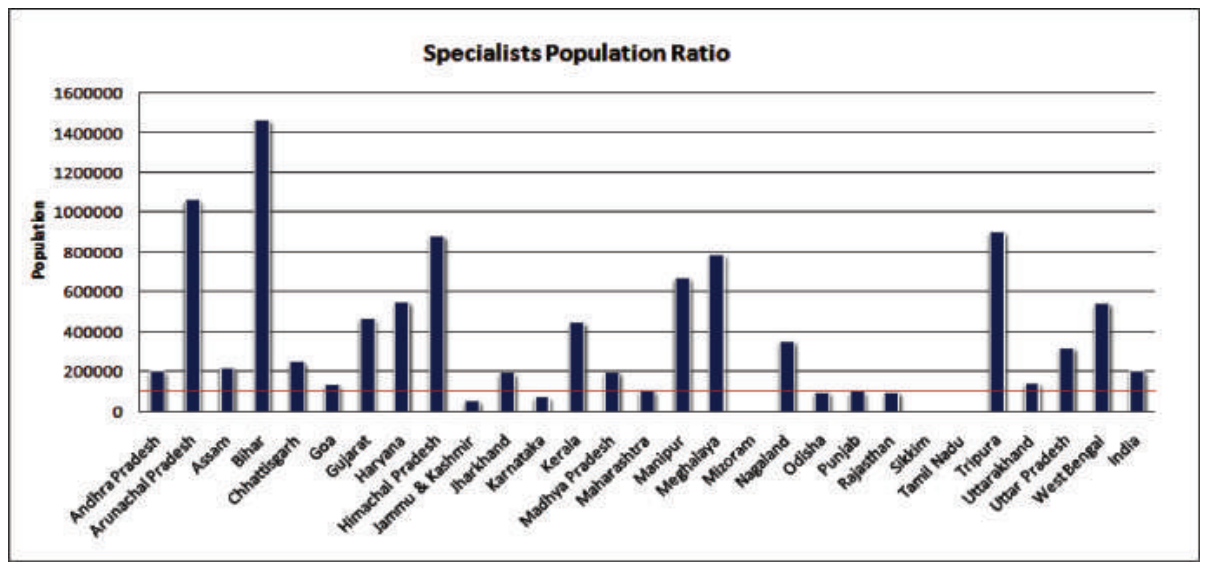

Figure 15:

As far as specialist ratio to the population at national level is concerned, India have a ratio of about one specialist per 2 lakh population which is much lower than the ratio of many states. 12 out of 29 states have ratio higher than national average. 
5.5. Disparities in the Accessibility: In terms of Road Accessibility and Connectivity

Health centre having all weather Motorable approach road is one of the important dimensions of accessibility of health centre to the people on one hand and connectivity to higher level health centres on the other. Unfortunately in some states many of the SCs and PHCs are without all weather Motorable approach road.

As fig - 16 shows that 22 out of 29 states still have SCs without proper road connectivity, with Arunachal Pradesh having highest percentage (63\%), followed by Uttarakhand (34\%), Jammu and Kashmir, Himachal Pradesh, Jharkhand, Uttar Pradesh, Nagaland, Manipur having above 25\% SCs without

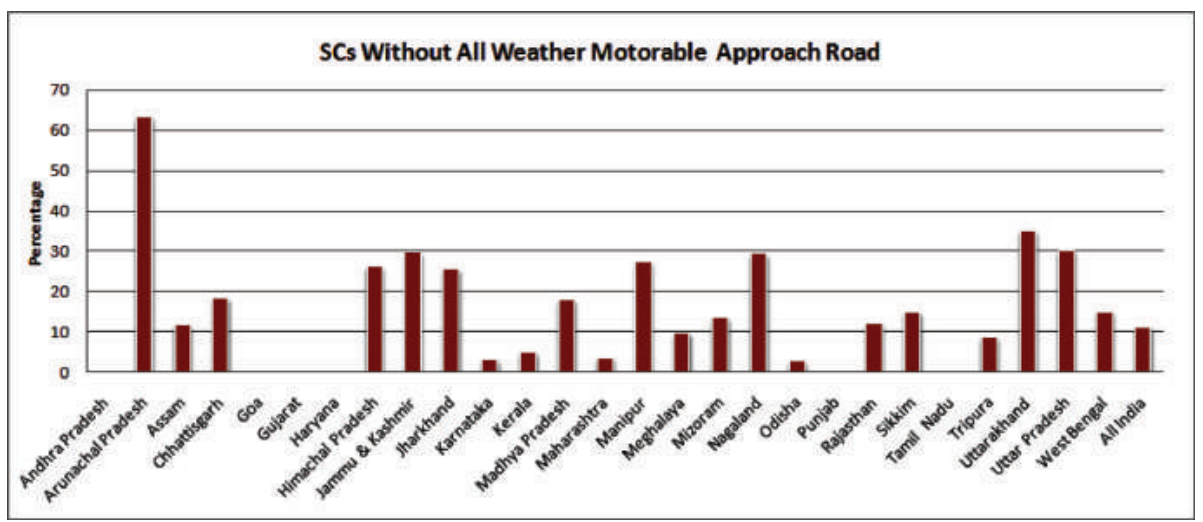

Figure 16:

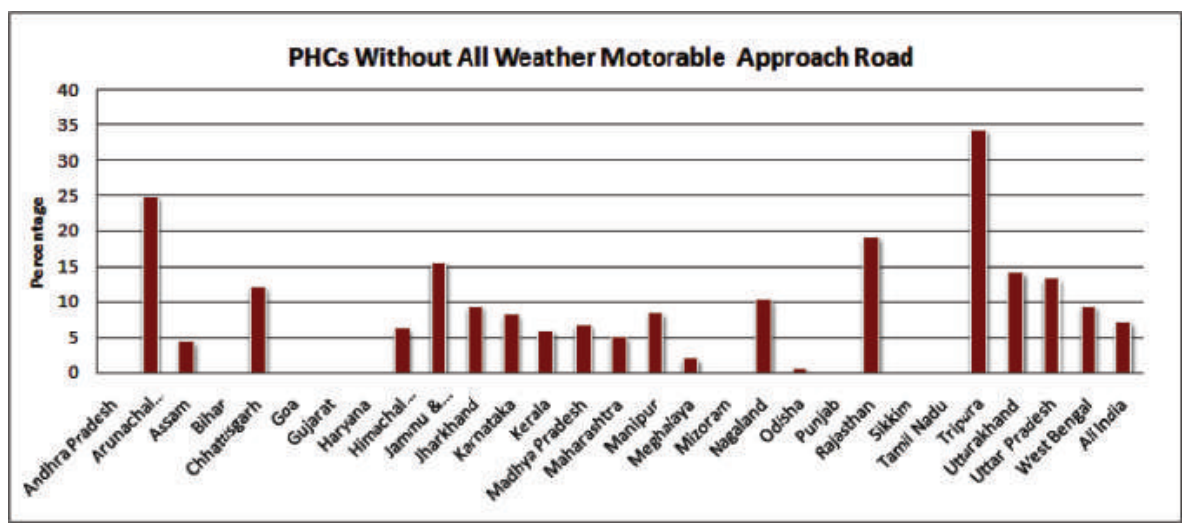

Figure 17:
Rural Healthcare Infrastructural Disparities in India: a Critical Analysis of Availability and Accessibility 
Taqi, $M$

Bidhuri, $\mathrm{S}$

Sarkar, $S$

Ahmad, WS

Wangchok, P

proper road connectivity. On an average there are about 10 percent SCs without proper road connectivity.

Looking at the PHCs without all weather Motorable approach road (fig - 17), 20 out of 29 states still have PHCs without proper road connectivity at varying degree. As far as national average is concerned about 8 percent of PHCs are without road connectivity. Comparing to the national average, Tripura and Arunachal Pradesh have highest percentage with 39 and 25\% respectively. Rajasthan, Jammu \& Kashmir and Chhattisgarh are also above the national average with 18,15 , and 12 percent PHCs respectively without proper road connectivity.

\section{CONCLUSION}

Healthcare infrastructure, be it physical or human resources forms a critical part of health service delivery in a whole healthcare system. Efficient and effective delivery of healthcare services depends on the availability and accessibility of health infrastructure for the people. Unfortunately health care system in rural India has remained inefficient and sub optimal even after decades of planned development. The country is lagging in terms of both availability and accessibility of healthcare infrastructure at all levels as revealed by the above discussion. Thus the major findings from the study can be summed under following sub headings.

\subsection{Availability of physical infrastructure and human resources.}

As far as availability of physical infrastructure is concerned only seven states viz. Jammu and Kashmir, Himachal Pradesh, Uttarakhand, Rajasthan, Goa and Kerala had surplus of SCs, PHCs and CHCs. But at the national level India still have 20\%, 22\% and 32\% shortfall in SCs, PHCs and CHCs respectively in rural areas.

On the other hand the situation of human resource availability is not much different as India have $32 \%$ and $81 \%$ shortfall at SCs and CHCs. About 10\% of the available PHCs in India are still functioning without a single doctor, added to that there is $36 \%$ shortfall in the paramedical staff at PHCs and CHCs with 13 states having shortfall above national average.

\subsection{Rural healthcare accessibility.}

Considering the accessibility of healthcare, the situation is not much better as most of the states in northern, central, and eastern India particularly Bihar and Uttar Pradesh are serving population much more than the average population as per specified population norms at all levels. Coming to the ratio 
of doctors to the population states like West Bengal, Uttar Pradesh, Jharkhand, Chhattisgarh, Madhya Pradesh etc. have a very poor ratio of population to doctors (i.e. above 1:50000), however most of the south, north, and north eastern states of India have an optimum ratio (i.e. below 1:30000). As far as ratio of specialists to population are concerned not a single state in the country has an optimum ratio. In some states like Bihar, Arunachal Pradesh, Himachal Pradesh, Meghalaya and Tripura the ratio is as high as above 1:800000 with Bihar being the highest I.e. 1:1400000. On the other hand states like Goa, Jammu and Kashmir, Karnataka, Maharashtra, Odisha etc has an optimum ratio of specialist to the population.

Accessibility to health centres through proper all weather road connectivity is as important as the availability of proper infrastructure. Unfortunately considering the facts, 22 out of 29 states in India still have SCs without proper road connectivity, on an average there are about 10 percent SCs without proper road connectivity. In terms of PHCs, 20 out of 29 states lack proper road connectivity. Nationally, 8 percent of PHCs in India does not have proper road connectivity.

Considering the above grim facts it can be finally concluded that healthcare infrastructure in India be it physical or human is inadequate and inefficient to cater the needs of rural population. Rural healthcare in India has always remained sub-optimal and has not reached to the level of satisfaction. However encouraging fact is that rural healthcare system in India has made terrific progress in the recent past. But the discouraging fact it that the progress has remained confined only to some states of the country (mostly south Indian states).

Such a grim situation of rural healthcare infrastructure may be attributed to many underlying factors, which includes inadequate budgetary provisions, administrative mismanagement, shortage of human resource, infrastructural inefficiency and the complacency unwillingness of the government among all. Further, there is no transparency and accountability in the functioning of these health institutions which keeps them at their lowest.

\subsection{Suggestions}

So the rural healthcare system in India needs a comprehensive overhaul in order to make it adequate and efficient so that rural people can take maximum benefit from it. Following feasible suggestion could be made in this direction.

1. Provide adequate budgetary provisions to health sector in order to overcome the shortfall of health centre's at various levels, because the present budget allocations for health sector is not sufficient to fulfill the needs of rural
Rural Healthcare Infrastructural Disparities in India: a Critical Analysis of Availability and Accessibility

$\longrightarrow$


Taqi, $M$

Bidhuri, $\mathrm{S}$

Sarkar, $S$

Ahmad, WS

Wangchok, P

masses. However national health policy 2017 aims to increase the public expenditure to $2.5 \%$ of GDP from current $1.4 \%$ which would hopefully improve the present situation.

2. Strengthen the regulatory mechanism and healthcare at any level should make to strictly follow the Indian Public Health Standards (IPHS) to ensure quality management and effective, economical and accountable healthcare delivery system.

3. Immediate need is to appoint the suitable Personnel where it is lacking.

4. Provide adequate facilities in the existing health centre.

\section{Limitations of the Study}

- The study is completely based on secondary data because it is impossible to collect primary data for such a large scale study.

- The analysis in present study is mostly quantitative and descriptive in nature. No specific statistical tools have been used.

- Data was not available on some of the other important parameters to assess the availability and accessibility of healthcare.

\section{REFERENCES}

[1] Chillimuntha A. K., Thakur K. R., Mulpari J. S., (2013) "Disadvantaged Rural Health - Issues and Challenges: A Review". National Journal of Medical Research, vol. 3, pp. 80-82.

[2] Evaluation Study of National Rural Health Mission (NRHM) in 7 States. Programme Evaluation Organization, Planning Commission, Government of India, New Delhi - 2011.

[3] Indian Public Health Standards (IPHS) Guidelines for Sub Centres, Primary Health Centres, and Community Health Centres, Directorate of General Health Services, Ministry of Health and Family Welfare, Government of India, 2012.

[4] Kumar A., and Gupta S., (2012) "Health Infrastructure in India: Critical Analysis of Policy Gaps in the Indian Healthcare Delivery”. Vivekananda International Foundation.

[5] Majumdar A., and Upadhyay V (2004) "Analysis of the Primary Healthcare System in India with Focus on Reproductive Healthcare Services". Artha Beekshan, Vol. 12, No. 04.

[6] Mavalankar D.V., Romanic K.V. et al. (2005) "Building the Infrastructure to reach and care for poor: Trends, Obstacles, and Strategies to overcome them". Centre for Management Services, IIM Ahmedabad.

[7] Reddy B.N., Prabhu G.R., Sai T. S. R., "Study on Availability on Physical Infrastructure and Manpower Facilities in Sub-centres of Chittor District of Andhra Pradesh”. Short Communication. Vol. 56, Issue 4, pp 290-292. 
[8] Rural Health Statistics 2015-16, Ministry of Health and Family Welfare, Statistics Rural Healthcare Division, Government of India.

Infrastructural

[9] Saika D. and Das K.K., "Access to Public Health-care in the Rural Northeast Disparities in India: India”. The NEHU Journal, Vol. XII, No. 2, July-December 2014, pp.77-100. a Critical Analysis

[10] Mohi Ud Din Javed, "Medical Geography of Pulwama District", M.Phil. Thesis, of Availability and Kashmir University, 1995.

Accessibility 